\title{
Towards Framework for Economic Value of Analytical Systems in Agriculture: Proposal of Research
}

\author{
J. Tyrychtr, P. Junek, V. Vostrovský, A. Vasilenko, J. Nouza \\ Faculty of Economics and Management, Czech University of Life Sciences Prague
}

\begin{abstract}
An important criterion for agricultural businesses and farmers who make investment decisions is the profitability of their investments. If the profitability criterion is applied to investments in analytical systems, problems arise with determining the exact value of such criteria. Special approaches for assessing the benefits of such systems must be used to cope with this problem. This paper focuses on the economic evaluation of analytical systems, whose economic impact in agriculture is unclear. Two main types of research approaches are identified: normative approach and positive approach to the evaluation of analytical systems. These approaches can be used to identify the benefits of analytical systems for agricultural activities, and to express their economic value for the management of agricultural enterprises. A new research process and research phases for the design of a conceptual framework for analytical systems' economic evaluation in agriculture is proposed based on this theoretical and research background.
\end{abstract}

\section{Keywords}

Analytical systems, economic value, decision support, information systems, agriculture.

Tyrychtr, J., Junek, P., Vostrovský, V., Vasilenko, A. and Nouza, J. (2016) "Towards Framework for Economic Value of Analytical Systems in Agriculture: Proposal of Research", AGRIS on-line Papers in Economics and Informatics, Vol. 8, No. 1, pp. 103 - 108. ISSN 1804-1930. DOI: 10.7160/aol.2016.080110.

\section{Introduction}

In connection with the agricultural business owners' awareness of their economic performance, the usage of analytical systems supporting decision making in agricultural activities is rising. Farmers themselves are constantly facing investment decisions which may improve their agricultural activities results. The profitability is an important criterion for the investment decision, but in the case of investment in analytical systems, it is not possible to determine it. The cost of the analysis systems (i.e. the cost of hardware, software, and to some extent staff costs) are represented by the market price. However, the benefits of the system (i.e. performance effects on the agricultural business) cannot be expressed directly. A measure identifying the yield development of analytic system can be used as an objective approach for evaluating the profitability of analytical systems. The result is better decision making about the analytic systems investment.

\section{Analytical systems}

Analytical systems in agriculture are used to support strategic decision making and for detecting hidden information for easy understanding and anticipating the needs of the farmers. The analytical system generally consists of three components (Ugolnitskii and Usov, 2008): a data storage component (database with analytical functions), a database of models (the models, methods, and simulated processes) and an expert system.

The data storage component is a cluster of databases containing all available data about the entire system and the problem to be analysed.

The model database contains separate models of subsystems and models describing the properties of the studied objects.

The expert system represents the knowledge base of control models (i.e. the database of specific agricultural situations prediction results, and a database of knowledge, experience and intuitions of experts in the field of agricultural activities). The first part contains known information from already existing control models (subsystems). This part includes a database of the prediction results of specific agricultural situations, obtained by using a previously created scenario. The second part of the expert component uses information, models and data based 
on knowledge, experience and intuition of experts in the field of agricultural activities. This section should be continually acquiring new data.

Currently, the most commonly used type of analytical systems are systems based on the principles of Business Intelligence (Chaudhuri et al., 2015, Azevedo and Santos, 2009, Tyrychtr et al., 2015). Business Intelligence is a set of processes, applications, and technologies that aim to effectively and efficiently support the decision-making processes in the company.

The data, information and knowledge storage in analytical systems may be addressed through the design of the so-called multidimensional databases. Multidimensional databases are suitable for storing (multidimensional) analytic data, which are most commonly used to carry out various analysis and reports required for the decision making (for example Tyrychtr et al., 2015b). Data in a multidimensional databases are organised using a data cube. The data cube is a data structure for storing and analysing large amounts of multidimensional data (Pedersen, 2009). The data cube consists of dimensions and measures. A dimension is a hierarchically structured set of values which provide the categorical information characterizing a particular aspect of the data (Pedersen, 2009b). Measures (indicators) of the cube are mainly quantitative data, which are the subject of the analysis.

\section{Evaluation of investments}

This paper deals with the problem of evaluation of investments in analytical systems. Analytical systems form a special category of systems - focusing primarily on decision support, while other systems typically have more features (such as the processing of operational data and other specific operational functions). For example, the automated weed system senses if a weed is present to deliver a precise amount of chemical spraying only the weed or the automated milking systems, which collect information on daily milk yield and feeding, provide farmers with the information about individual performance of each cattle (in order to support decision -making about inseminations and exchange of cattle). The reduced costs resulting from these applications are obvious and may act as a motivation for investing in such system. On the contrary, operating costs reduced due to the use of the analytical system are modest, which means that most of the advantages of the analytical system must come from the less tangible benefits. Therefore, the evaluation of the investment to the analytical system must go beyond the traditional analysis of costs and revenues.

The standard method for the evaluation of investment is the cost and revenue analysis. For example, the investment in job cuts is assessed by comparing the performance of employees with the expected performance of the machines. On the basis of a comparison of labour costs with amortisation, interest and maintenance costs the appropriate investment is selected. However, this traditional approach is difficult to use for the evaluation of analytical systems, primarily due to a wide range of decisions and actions which may be affected by information from the analytical system (King et al., 1990) and the key role of the user of the system (Hamilton and Chervany, 1981). There distinguish three levels of benefits (Parker et al., 1988): tangible, quasi-tangible and intangible benefits. This classification of quasi-tangible and intangible effects is more visible - allowing a better evaluation of alternative investments into analytical systems.

In general, the problem of information systems evaluation is addressed in many publications outside of agriculture (Kleijnen, 1980, Kleijnen, 1984, Hamilton and Chervany, 1981, Banker and Kauffman, 1989, Kauffman and Weill, 1989) and only a few in the field of agriculture (King et al., 1990, Streeter and Hornbaker, 1993). Based on the available literature, it is possible to identify two main types of research approaches (Fig. 1), (Verstegen et al., 1995): normative and positive approaches.

Normative approaches provide a theoretical examination of the expected or desired profitability of the analytical systems on the basis of the net revenues from their functions (e.g. better decisions on labour savings) and on some predetermined decision-making criteria (Kleijnen, 1980). Normative approaches are further distinguished in decision-making based on theoretical approaches (analysis of the decision-making trees, Bayesian information economics, theory of control) and decision making based on the analytical approaches (simulation, linear programming and dynamic programming).

Positive approaches investigate the expected profitability through empirical studies. Examples are experimental, quasi-experimental, and non-experimental designs. In the context of the experimental design group it is possible to distinguish between the field experiments and experimental economics. 


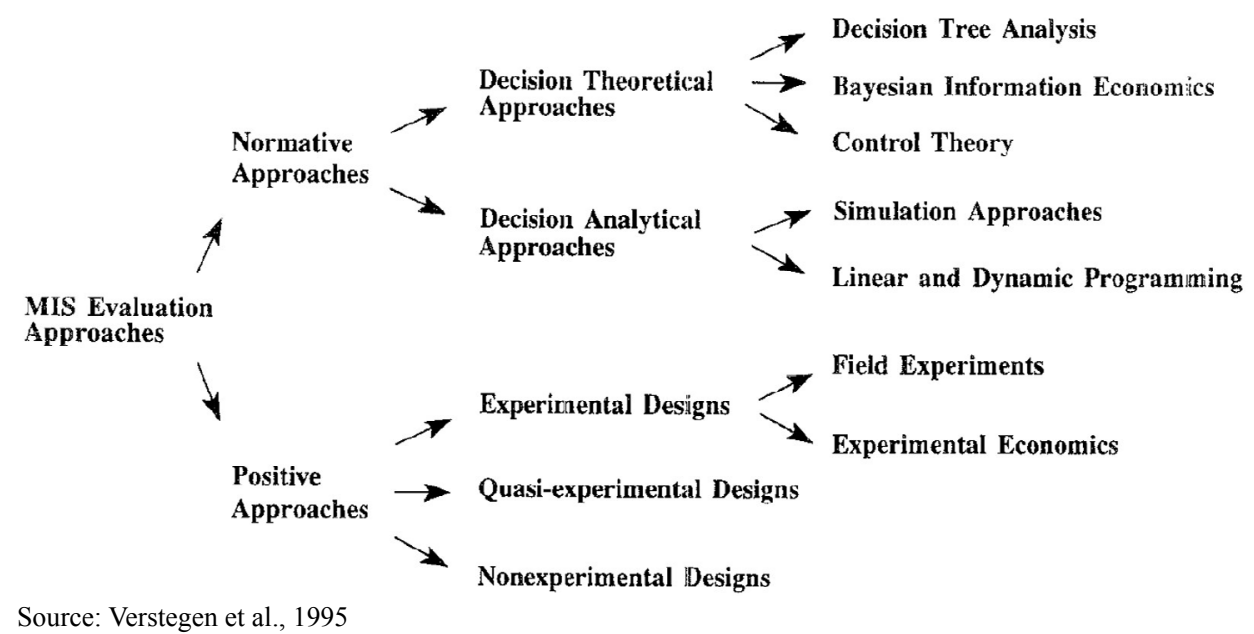

Figure 1: A classification of evaluation approaches.

Normative approaches are currently considered as limited due to their potential in practice. On the contrary, positive approaches depends greatly on the availability and quality of the data base and the type of analytical intent. Experimental economics is considered to be an interesting alternative as means of streamlining decision making in the highly controllable environment. All of these approaches must be reviewed in the context of analytical systems in agriculture.

The purpose of this paper is to present a research process aimed to create a conceptual framework for the identification of the economic value of analytical systems for agricultural entities.

\section{Materials and methods}

Relevant publications were identified after searching scientific databases: Web Of Science, Scopus, ScienceDirect and SpringerLink. Screening of titles, abstracts and conclusions was performed independently by all co-authors. Studies defining the problems of evaluation of information systems investments were requested in order to be included in the review. Studies linked with the issue of evaluation of investment in specific types of systems, applications, and technologies in the agriculture (e.g. geographic information system, specialized automated systems, etc.) were rejected from the review. Mainly the following search terms were used: analytical systems, investments in information systems including the field of agriculture, economic value of information systems, economics of information systems and Business Intelligence.

\section{Results and discussion}

Based on the review of the relevant and existing research in the area of evaluation of investment in analytical systems in agriculture, the following shortcomings of the current situation were identified.

Identification of the shortcomings of the current state

- No comprehensive survey evaluating the state of analytical systems in the field of agriculture has been processed yet.

- There is a considerable amount of issues accompanying the operation of analytical systems activities on a highly skilled level.

- The economic potential of analytical systems and their contribution to agriculture has not been described yet

- No attention has been paid to the research in the area of the conceptual framework for the economic evaluation of analytical systems.

- With the development of computer and information literacy of the managerial staff in the agricultural enterprises, greater acceptance of new analytical systems can be expected in the future, which requires the analysis and reflection of new ways of working with analytical data in the agricultural sector

In this paper, a new research procedure is proposed to cope with these problems. It specifies the individual methodological phases of this research issue: 
1. Analysis of the analytical systems state in agriculture. A questionnaire survey among the agricultural enterprises and small farmers should be performed at this stage. After the survey, a basic exploratory analysis of survey results must be carried out to verify the dependencies by using the Pearson and M-V Chi-square test, which will be used to verify the connection between the structure of the company and the use of analytical systems. The working and statistical hypotheses must be formulated. The analysis will follow the previous research (Tyrychtr et al., 2015), which was focused only on a narrow type of analytical systems - Business Intelligence.

2. Identification of performance indicators. At this stage, it is necessary to analyse the capabilities of analytical systems in various sectors of agriculture. The economic and performance indicators of analytical systems are identified, including the expert and knowledge based subsystems.

3. Classification of evaluation approaches. In this phase, the evaluation approaches to determine the economic value of analytical systems for decision support in agricultural enterprises are classified. The methods of information systems evaluation are applied (Banker and Kauffman, 1989, Hamilton and Chervany, 1981, Kauffman and Weill, 1989, Kleijnen, 1980, Kleijnen, 1984), including methods focused on applications in agriculture (King et al., 1990, Streeter and Hornbaker, 1993). Two main types of research approaches will be applied in this research: normative and positive approaches. Normative approaches provide a theoretical examination of the expected or desired profitability of the analytical systems on the basis of the net revenues from their functions and on some predetermined decision-making criteria (Kleijnen, 1980). Normative approaches are further distinguished in decisionmaking based on theoretical approaches (analysis of the decision-making trees, Bayesian information economics, theory of control) and decision making based on the analytical approaches (simulation, linear programming and dynamic programming). Positive approaches investigate the expected profitability through empirical studies.
Examples are experimental, quasiexperimental, and non-experimental designs. All of these proposals must be examined in the research

4. Application of analytical systems. A draft of the possible applications of analytical systems including expert and knowledge based subsystems is proposed and the benefits of such systems for agricultural enterprises are defined. Within this phase, specific scientific methods (simulation, mathematical methods) and modelling techniques (multidimensional databases, knowledge and process modelling) are used.

5. Design of a conceptual framework. The above phases and their synthesis allow the design of a new conceptual framework for the economic evaluation of analytical systems in agriculture.

6. Acceptance. The objective of this phase is the systematic experimentation with the design process of a new conceptual framework.

7. Application. The newly created and adopted conceptual framework is validated in real standardized agricultural enterprises and farms.

8. Approval. This dynamic phase takes place together with the application phase. The goal of this phase is the maintenance of the new conceptual framework in order to adapt it in the constantly changing environment of the various analytical systems.

9. Research evaluation. The benefits of the newly proposed conceptual framework are evaluated on the basis of the outputs of the research plan.

To comply with the above procedure, it is appropriate to diversify and to specify the stages of the research. The following Table 1 shows the stages in accordance with the project management of research.

The expected benefits of the proposed research procedure

The design of a new conceptual framework for the economic evaluation of analytical systems allows enhancing the efficiency of agricultural enterprises. The resulting conceptual framework will streamline the decision-making of agricultural enterprises in the area of investments in analytical systems. 


\begin{tabular}{|l|l|}
\hline Title & Description \\
\hline Literature review & $\begin{array}{l}\text { Collection of the underlying data for the analysis, the study of scientific articles } \\
\text { and professional publications, formulation of hypotheses. }\end{array}$ \\
\hline $\begin{array}{l}\text { Preparation of the survey } \\
\text { and data base }\end{array}$ & $\begin{array}{l}\text { Preparation of the data base for the analysis of the evaluation of the analytical systems } \\
\text { economic value and the preparation of the questionnaire survey for agricultural managers. }\end{array}$ \\
\hline $\begin{array}{l}\text { Analysis and evaluation } \\
\text { of data }\end{array}$ & $\begin{array}{l}\text { Cleaning, sorting and statistical evaluation of the data from the questionnaire survey } \\
\text { of the state of analysis systems in agriculture. }\end{array}$ \\
\hline $\begin{array}{l}\text { Classification and analysis } \\
\text { of evaluation approaches }\end{array}$ & $\begin{array}{l}\text { Classification and analysis of the strengths and weaknesses of the evaluation approaches } \\
\text { for determining the economic value of analytical systems. }\end{array}$ \\
\hline $\begin{array}{l}\text { Dissemination of } \\
\text { preliminary results }\end{array}$ & $\begin{array}{l}\text { Publication of articles about the state of analytical systems in agriculture and their economic } \\
\text { evaluation. Presentations at conferences. }\end{array}$ \\
\hline $\begin{array}{l}\text { Evaluation of analytical } \\
\text { systems }\end{array}$ & $\begin{array}{l}\text { Evaluation of analytical systems, including expert and knowledge based subsystems and their } \\
\text { benefits to agricultural entities. }\end{array}$ \\
\hline $\begin{array}{l}\text { Design of conceptual } \\
\text { framework }\end{array}$ & Design of a new conceptual framework and its evaluation. \\
\hline Dissemination of results & Publication of articles, active participation in conferences and seminars. \\
\hline
\end{tabular}

Source: self-authored

Table 1: Suggested research stages.

The main benefits of the proposed research are the following:

- The project will evaluate the state of analytical systems in the field of agriculture.

- The evaluation approaches, possible analytical systems applications in agriculture and their economic potential and contribution to agricultural enterprises will be classified.

- A new innovative conceptual framework for the economic evaluation of analytical systems in agriculture will be designed.

- $\quad$ The research plan will efficiently and effectively support the business activities at the level of the strategic management of agricultural enterprises in relation to the economic aspects of analytical systems.

On the basis of the above mentioned benefits of the proposed research procedure, agricultural subjects will be able to invest in economically beneficial analytical systems which will enable obtaining of analytical data through special outputs in a more efficient way. For example, to track information about total production, costs or consumption over time for the whole enterprise or its part, perform different types of analysis (factor - factor, breeding optimisation, the analysis of the efficiency of plant protection products, etc.) and create additional special analytical outputs which provide additional economic benefits.

The newly created concepts in economic evaluation of analytical systems are supposed to provide methodological support for a better design of agricultural analytical systems, agricultural expert systems and knowledge based systems and to contribute to the overall efficiency of agricultural enterprises and the entire agricultural sector of the Czech Republic.

\section{Conclusion}

In this paper, a new research procedure for the design of a conceptual framework for analytical systems' economic evaluation in agriculture was proposed. There was used theoretical and research background to map the current state of evaluation approaches regarding analytical systems in agriculture, and to elicit future research avenues in terms of design science framework for economic value of analytical systems in agriculture. According to the performed literature review and previous research, the area of analytical systems in the field of agriculture appears as a prospective research subject.

Purposes of this paper was threefold: the literature review may help economical informatics researchers get an overview of this active research domain; proposal of research facilitates the understanding of different research streams; finally, the proposed future topics may guide researchers in identifying promising research avenues.

\section{Acknowledgements}

The results and knowledge included herein have been obtained owing to support from the Internal grant agency of the Faculty of Economics and Management, Czech University of Life Sciences in Prague, grant no. 20161019, "Economic value of analytical systems in agriculture". 
Corresponding author:

Ing. Jan Tyrychtr, Ph.D.

Department of Information Technologies, Faculty of Economics and Management

Czech University of Life Sciences in Prague, Kamýcká 129, Prague 6-Suchdol, Czech Republic

Email: tyrychtr@pef.czu.cz

\section{References}

[1] Azevedo, A. and Santos, M. F. (2009) "Business Intelligence-State of the Art, Trends, and Open Issues", In: $1^{\text {st }}$ International Conference on Knowledge Management and Information Sharing, KMIS, pp. 296-300. ISBN: 978-989674013-9.

[2] Banker, R. D. and Kauffman, R. J. (1989) "Quantifying the Business Value of Information Technology: Research on Information Systems", Information Systems Working Papers Series. [Online] Available: http://ssrn.com/abstract=1289044 [Accessed: 10 March 2016].

[3] Chaudhuri, S., Dayal, U. and Narasayya, V. (2011) "An overview of business intelligence technology", Communications of the ACM, Vol. 54, No. 8, pp. 88-98. ISSN 00010782.

[4] Hamilton, S. and Chervany, N. L. (1981) "Evaluating Information System Effectiveness-Part I: Comparing Evaluation Approaches", MIS Quarterly, pp. 55-69. ISSN 02767783.

[5] Kauffman, R. J. and Weill, P. (1989) "An Evaluative Framework for Research on the Performance Effects of Information Technology Investment". Information Systems Working Papers Series. [Online] Available: http://ssrn.com/abstract=1289699 [Accessed: 10 March 2016].

[6] King, R. P, Harsh, S. B and Dobbins, C. L. (1990) "Farm Information Systems: Farmers' Needs and System Design Strategies", Tijdschrift Voor Sociaal Wetenschappelijk Onderzoek Van De Landbouw, Vol. 5, No. 1, pp. 34-59. ISSN 0921-481X.

[7] Kleijnen, J. P. (1980) "Computers and profits: Quantifying Financial benefits of information". Addison-Wesley Longman Publishing Co., Inc. ISBN: 0201038137.

[8] Kleijnen, J. P. (1984) "Quantifying the Benefits of Information Systems", European Journal of Operational Research, Vol. 15, No. 1, pp. 38-45. ISSN 03772217.

[9] Parker, M. M, Benson, R. J and Trainor, H. E. (1988) "Information Economics: Linking Business Performance to Information Technology", Prentice Hall. Englewood Cliffs, NJ. ISBN 0134645952.

[10] Pedersen, T. B. (2009) "Encyclopedia of Database Systems". Ling L., Özsu, T. M. USA: Springer US, Multidimensional Modeling, pp. 1777-1784. ISBN 978-0-387-35544-3.

[11] Pedersen, T. B. (2009b) "Encyclopedia of Database Systems". Ling L., Özsu, T. M. USA: Springer US, Dimension, pp. 836-836. ISBN 978-0-387-35544-3.

[12] Streeter, D. H and Hornbaker, R. H. (1993) "Value of Information Systems: Alternative Viewpoints and Illustrations". In: Farm Level Information Systems, Wageningen Academy Publishers, Wageningen, pp. 283-293. ISBN 9067544388.

[13] Tyrychtr, J., Ulman, M. and Vostrovský, V. (2015) "Evaluation of the State of the Business Intelligence among Small Czech Farms", Agricultural Economics, Vol. 61, No. 2, pp. 63-71. ISSN 0139-570X.

[14] Tyrychtr, J., Brožek, J. and Vostrovský, V. (2015b) "Multidimensional Modelling from Open Data for Precision Agriculture". In: Enterprise and Organizational Modeling and Simulation, Springer International Publishing, pp. 141-152. ISBN 978-3-319-24625-3.

[15] Ugolnitskii, G. A. and Usov, A. B. (2008) "Information-Analytical System for Control of EcologicalEconomic Objects", Journal of Computer and Systems Sciences International, Vol. 47, No. 2, pp. 321-328. ISSN 1064-2307.

[16] Verstegen, J.A.A. M., Huirne, R. B. M., Dijkhuizen, A. A. and Kleijnen, J. P. C. (1995) "Economic value of management information systems in agriculture: a review of evaluation approaches". Computers and electronics in agriculture, Vol. 13, No. 4, pp. 273-288. ISSN 01681699. 